\title{
Pengaruh Suhu pada Pengeringan Tepung Kimpul (Xanthosoma sagittifolium)
}

\author{
Endah Sulistiawati ${ }^{1, *}$, Imam Santosa ${ }^{1}$, Yunizar Rizka APS ${ }^{1}$, Arya Aji saka ${ }^{1}$ \\ ${ }^{1}$ Program Studi Teknik Kimia, Fakultas Teknologi Industri, Universitas Ahmad Dahlan, Kampus 3, Jl. Prof. \\ Dr. Soepomo, SH., Janturan, Warungboto, Yogyakarta 55164 \\ *email: endahsulistiawati@che.uad.ac.id
}

\begin{abstract}
Abstrak
Taro flour can be used as an alternative for wheat. This study aims to determine the optimal conditions on the operation of the drying resulting in minimal water content, but did not damage the properties of the desired material. This research will be obtained the parameters that can be used to design a dryer with a larger scale. After the taro peeled, washed, chopped and soaked with a solution of salt. Samples inserted into a dryer equipped with a balance, so that it can be read sample weight at a certain time. The drying process is stopped until the weight remains. The process of making flour baked, steamed after soaking the taro, and then do the drying process as the raw flour. The variables studied were temperature drying. The result showed that higher drying temperatures will accelerate the achievement of equilibrium moisture content, which means the drying operation requires a shorter period of time. Lower value of equilibrium moisture content on 0,02 ( $g$ water / $g$ dry matter) can be achieved at a temperature of $90^{\circ} \mathrm{C}$, with a time of 80 minutes.
\end{abstract}

Keywords: drying, taro powder

\section{Pendahuluan}

Tanaman kimpul (Xanthosoma sagittifolium) mudah tumbuh di beberapa daerah di Indonesia. Penelitian ini membuat tepung dari umbi kimpul yang dapat digunakan sebagai alternatif pengganti terigu. Diharapkan tepung tersebut dapat digunakan sebagai bahan baku pada pembuatan roti, kue, atau mie, sehingga dapat mengurangi tingkat ketergantungan terhadap impor gandum. Proses pembuatan tepung memerlukan suatu tahapan pengeringan. Agar bahan dapat bertahan lama diupayakan kadar air yang minimal. Di masyarakat pada umumnya mengandalkan sinar matahari untuk mengeringkan bahan. Jika musim kemarau hal ini dapat dilakukan dengan mudah, namun bila musim penghujan tiba maka akan sulit dilaksanakan, atau bahan akan kering dalam waktu yang lama dan kualitas yang dihasilkan kurang bagus. Akibatnya banyak hasil tanaman pasca panen yang membusuk karena tidak tahan disimpan.

Dehidrasi bahan pangan telah dipraktekkan selama berabad-abad, dan manajemen yang tepat dari produk pertanian dan sumber daya energi sekarang membutuhkan pemahaman yang lebih baik dari proses pengeringan bahan biologis [1]. Proses pengeringan yang merupakan salah satu bagian dari cara pembuatan tepung kimpul memegang peranan yang sangat penting. Pengeringan yang dilakukan seperti pada penjelasan Saptoningsih [2] menggunakan sinar matahari, dijemur di atas para-para. Di dunia industri penggunaan sinar matahari memiliki kelebihan dan kelemahan. Kelebihannya penggunaan energi yang hemat. Sementara kelemahannya tidak bisa dilakukan jika musim penghujan tiba.

Laju pengeringan (kinetika pengeringan) suatu bahan akan menentukan ukuran alat yang digunakan di skala industri, yang secara langsung dapat mempengaruhi harga alat dan biaya pengoperasiannya. Laju pengeringan juga akan mempengaruhi kualitas produk yang telah dikeringkan, karena ada berbagai fenomena yang menyertai, antara lain perpindahan panas dan mengecilnya ukuran karena kadar air yang berkurang. Informasi dasar yang harus diberikan pada proses pengeringan adalah kurva pengeringan (drying curve). Kurva ini menjelaskan kinetika pengeringan dan bagaimana perubahan selama proses pengeringan. Kurva ini dipengaruhi oleh sifat bahan, ukuran dan ketebalan bahan yang akan dikeringkan, dan kondisi pengeringan. Teknik pengambilan sampel untuk menentukan kurva pengeringan pada tray dryer yaitu dengan cara mencatat kadar air sampel awal, dan setiap waktu tertentu, hingga pengeringan selesai. Cara gravimetri adalah cara yang paling sering digunakan. Ukuran sampel, suhu, dan waktu pengeringan adalah faktor yang penting [3].

\section{Metodologi}

Bahan yang digunakan meliputi: Umbi kimpul, garam dapur, akuades. 
Alat yang dipakai yaitu: Pisau, baskom, alat pengering (oven) yang dilengkapi dengan neraca, dan parut.

\section{Cara Penelitian}

Proses pembuatan tepung mentah dapat dilihat pada gambar 1 .

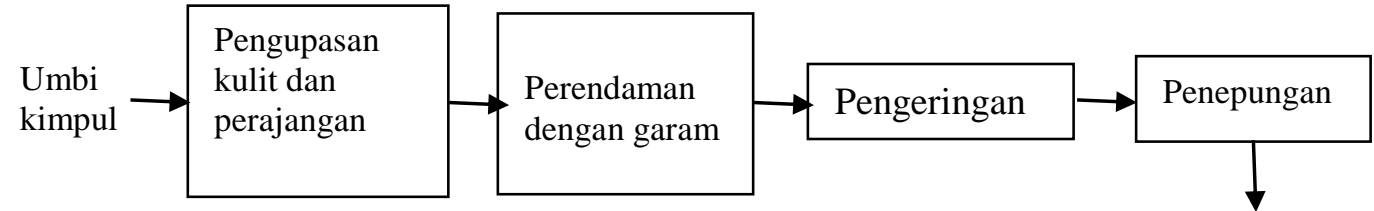

Gambar 1. Proses pembuatan tepung kimpul

\section{Analisis Hasil}

Setelah umbi kimpul dikupas, dicuci bersih, dirajang dan direndam dengan larutan garam dapur, setelah itu diparut. Sampel umbi dimasukkan ke alat pengering yang dilengkapi dengan neraca, sehingga dapat dibaca berat sampel pada waktu tertentu. Proses pengeringan dihentikan hingga berat tetap. Variabel yang diteliti adalah suhu pengeringan.

\section{Hasil Penelitian dan Pembahasan}

Eksperimen dilakukan di laboratorium Teknik Kimia. Sampel umbi kimpul dengan berat kira-kira 5 gram dikeringkan dalam oven dilengkapi dengan neraca, agar diketahui berat bahan pada waktu yang diinginkan. Percobaan dilakukan pada berbagai suhu operasi pengeringan, yaitu: $60,70,80,90$, dan $100{ }^{\circ} \mathrm{C}$. Berat bahan basah dan gelas arloji mula-mula dicatat, selanjutnya setiap selang waktu 10 menit berat bahan dan gelas arloji dicatat. Kadar air didefinisikan sebagai selisih berat dari bahan basah dengan bahan kering. Yang dipakai sebagai pembanding adalah berat bahan (kimpul) terkering yang dapat dicapai pada seluruh pengeringan. Dari penelitian ini, berat kimpul terkering adalah 1 gram, dari berat basah total 5 gram (diperoleh pada operasi pengeringan suhu $90{ }^{\circ} \mathrm{C}$ ). Jika dihitung kadar airnya (basis basah) akan diperoleh kadar air pada berbagai suhu operasi yang dapat dilihat pada gambar 2.

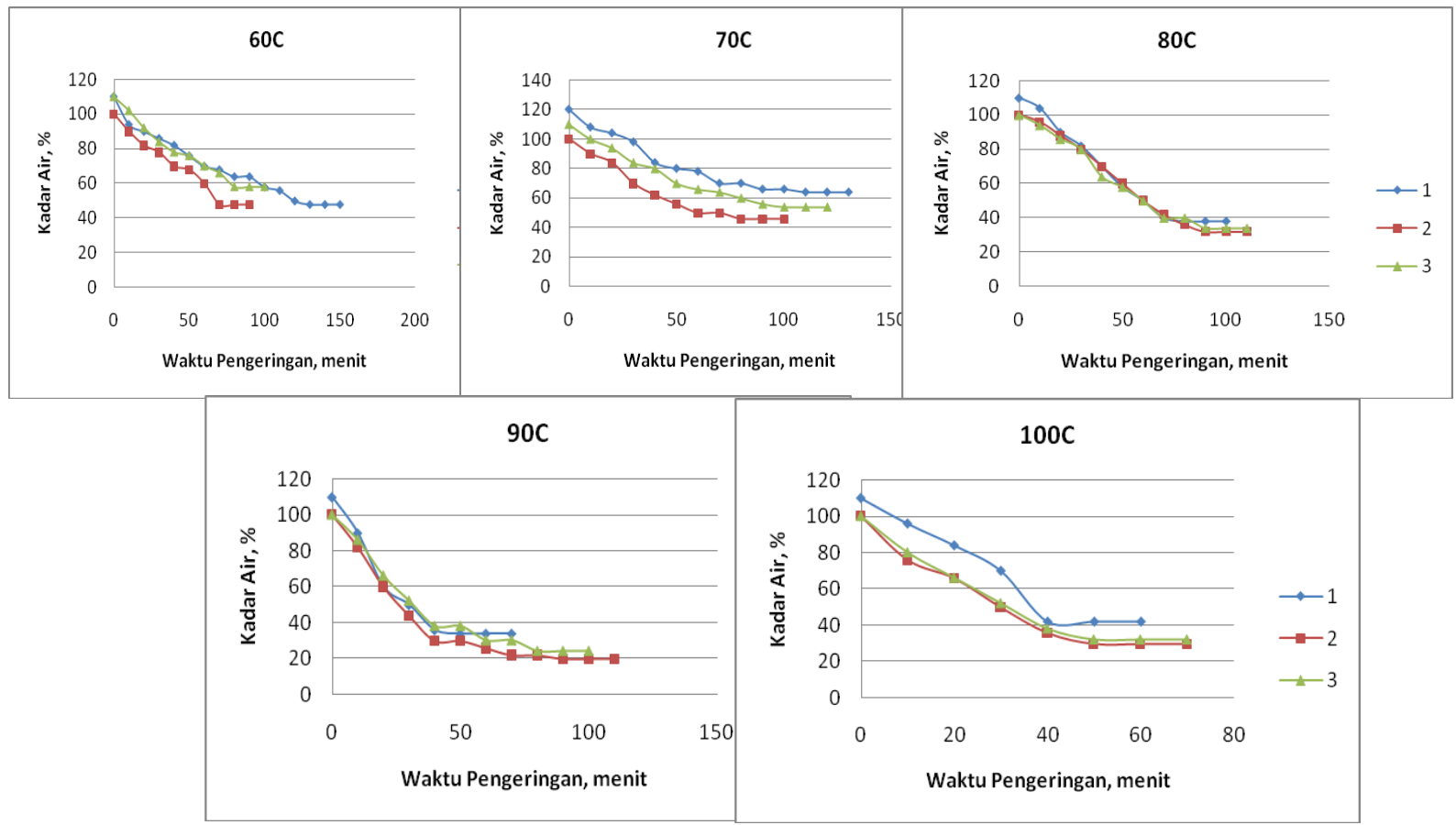

Gambar 2. Kadar Air Sebagai Fungsi Waktu Pengeringan Pada Berbagai Suhu.

Dari data pengeringan dengan kadar air basis basah, selanjutnya dinyatakan dalam kadar air basis kering, yang cara menghitungnya melalui persamaan 1 


$$
W_{d}=\frac{W_{w}}{1-W_{w}}
$$

dengan:

$$
\begin{aligned}
& W_{d}=\text { Kadar air basis kering, } \mathrm{g} \text { air/(g bahan kering) } \\
& W_{w}=\text { Kadar air basis basah, } \mathrm{g} \text { air/(g bahan basah). }
\end{aligned}
$$

Korelasi antara kadar air basis basah dan basis kering dapat dilihat pada gambar 3.

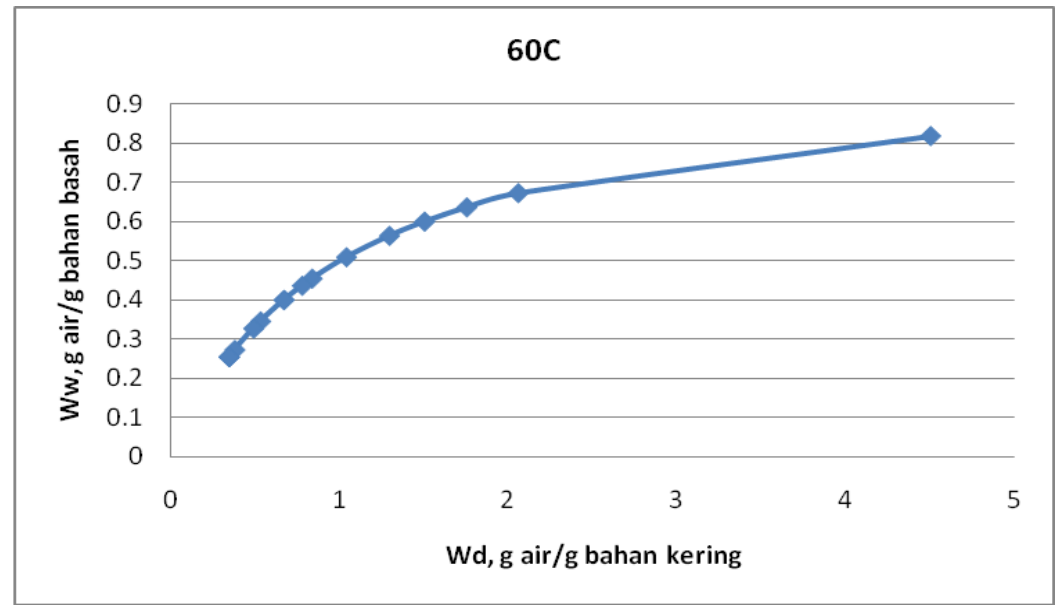

Gambar 3. Korelasi antara kadar air basis basah dengan kadar air basis kering

Nilai kadar air keseimbangan terendah yaitu 0,02 (g air/g bahan kering) dapat dicapai pada suhu $90{ }^{\circ} \mathrm{C}$, dengan waktu 80 menit.

Kecepatan pengeringan N, didefinisikan sebagai banyaknya air di dalam bahan yang teruapkan per satuan berat bahan kering per satuan waktu. Persamaan yang diigunakan untuk menghitung adalah persamaan (2).

$$
\mathrm{N}=\frac{\text { berat air yang teruapkan, } \mathrm{g}}{\text { (berat bahan kering, } \mathrm{g}) \cdot(\text { waktu, menit) }}
$$

Dari data kadar air pada suhu $60,70,80,90$, dan $100^{\circ} \mathrm{C}$ diolah untuk mendapatkan kecepatan pengeringan. Hasil dapat dilihat dalam bentuk grafik pada gambar 4 .

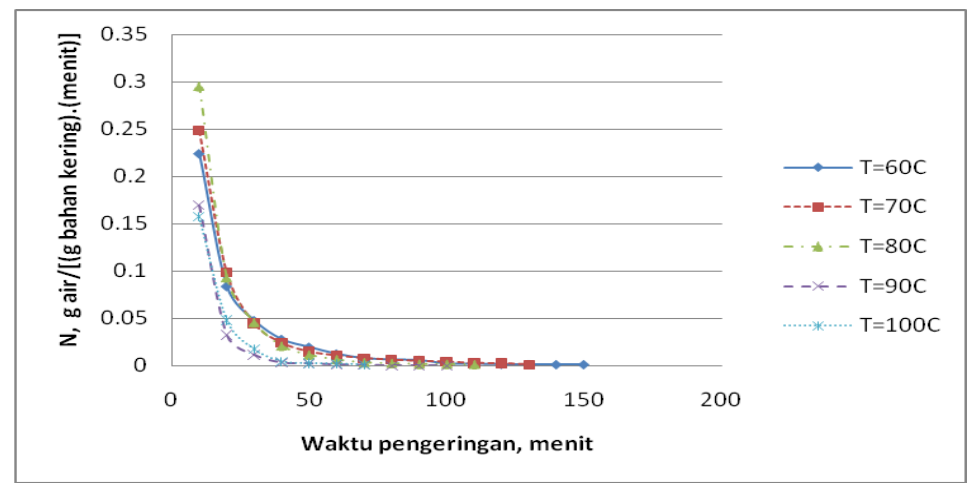

Gambar 4. Kecepatan pengeringan sebagai fungsi waktu pada berbagai suhu

Dari gambar 4. dapat dilihat bahwa untuk mendapatkan kecepatan pengeringan yang sama jika suhu lebih tinggi maka akan dicapai pada waktu yang lebih singkat. Suhu $60{ }^{\circ} \mathrm{C}$ memerlukan waktu 150 menit, sedangkan suhu $100{ }^{\circ} \mathrm{C}$ memerlukan waktu 60 menit. Kecepatan pengeringan akan meningkat dengan peningkatan suhu, ini sesuai dengan hasil penelitian Islam et al. [4], artinya MR yang dicapai lebih rendah untuk waktu yang sama. 
Pada percobaan pengeringan umbi kimpul dilakukan pula pengeringan dengan selang waktu data yang diamati setiap 3 menit, suhu pengeringan $100{ }^{\circ} \mathrm{C}$. Hasil perhitungan Moisture Ratio (MR), yaitu perbandingan kadar air pada saat $t$ dengan kadar air mula-mula dapat dilihat pada gambar 5. Pada gambar 5 tersebut persamaan yang diperoleh merupakan persamaan linear.

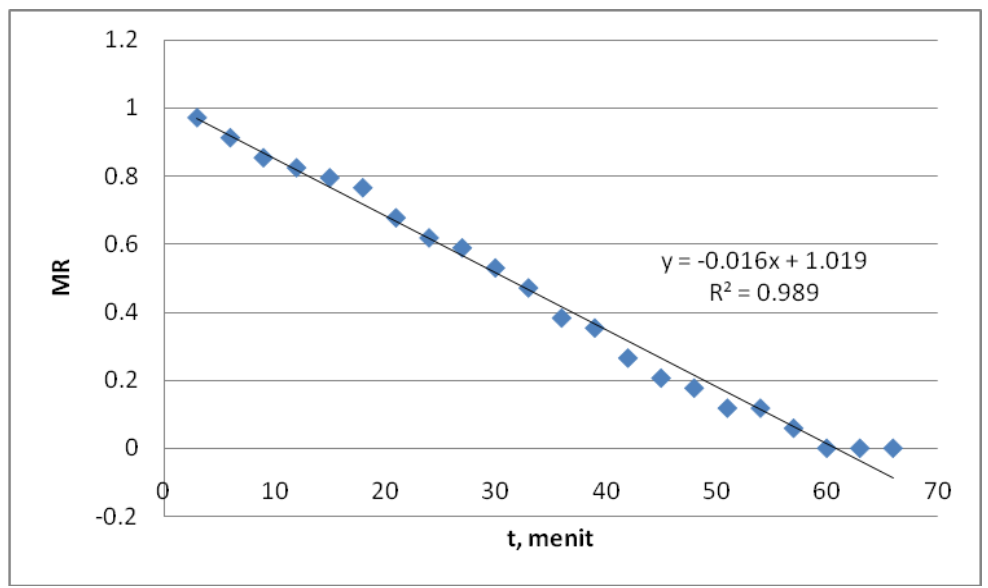

Gambar 5. Hubungan Moisture Ratio (MR) tepung mentah dengan waktu pengeringan pada suhu $100^{\circ} \mathrm{C}$

\section{Kesimpulan}

Dari hasil penelitian diperoleh suhu pengeringan yang lebih tinggi akan mempercepat tercapainya kadar air keseimbangan, yang berarti operasi pengeringan memerlukan waktu yang lebih singkat. Nilai kadar air keseimbangan terendah yaitu 0,02 (g air/g bahan kering) dapat dicapai pada suhu $90^{\circ} \mathrm{C}$, dengan waktu 80 menit.

\section{Ucapan Terima Kasih}

Penulis mengucapkan terima kasih kepada Universitas Ahmad Dahlan yang telah mendanai seluruh aktivitas penelitian ini.

\section{Daftar Pustaka}

[1] E. J. Forsdyke, B. Rackham, et al. 1945, "Pottery and porcelain". Encycl. Br. 18, 338-373 and XLIII.

[2] Saptoningsih, 2013, "Membuat Tepung Talas dan alternatif Pemanfaatannya", http://bbpplembang.info/index.php/arsip/artikel/artikel-pertanian/723-membuat-tepung-talas-dan-alternatifpemanfaatannya diakses tanggal 14 Nov 2014.

[3] Genskow, L.R., Betmesch, W.E., Hecht, J.P., Kemp., I., Langrish, T., Schwartzbach, C., Smith, F.L., 2008, 'Perry's Chemical Engineers' Handbook: Psychrometry, Evaporative Cooling, and Solids Drying”, 8 ed., Sec.12, pp. 29, McGraw-Hill Companies, Inc., USA.

[4] Islam, M.S., Haque, M.A., and Islam, M.N., 2012, "Effects of Drying Parameters on Dehydration of Green Banana (Musa sepientum) and its Use in Potato (Solanum tuberosum) Chips Formulation", The Agriculturists 10 (1): 87-97. 